DIEGO GIOAVANNI BERMÚDEZ AGUIRRE

DEPARTAMENTO DE ARTE,

ARQUITECTURA Y DISEÑO

FACULTAD DE HUMANIDADES

Y CIENCIAS SOCIALES

PONTIFICIA UNIVERSIDAD JAVERIANA CALI

CALI, COLOMBIA

DGBERMUDEZ@JAVERIANACALI.EDU.CO

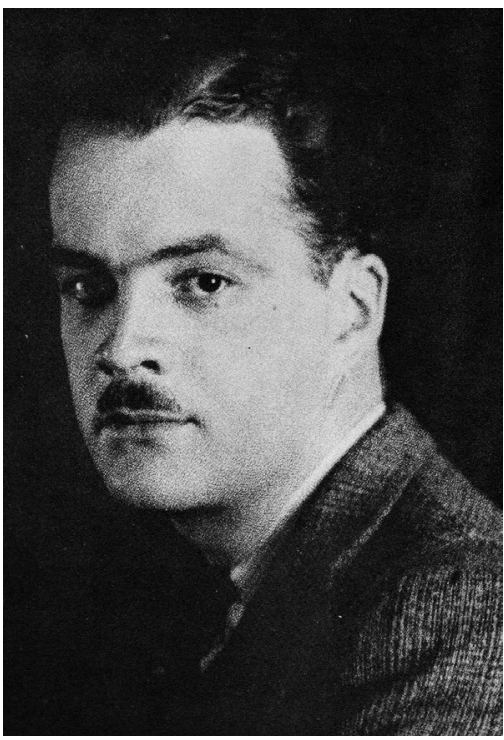

Figura 1. Retrato Santiago Martínez Delgado. Fuente: Piñeros, 1974.

\section{Santiago Martínez Delgado, pionero del diseño gráfico colombiano: una reseña de su vida y obra}

Santiago Martínez Delgado, Pioneer of Colombian Graphic Design: A Review of his Life and Work

Nacido en Bogotá en 1906, en el seno de una familia colombiana de importantes personalidades entre las que destacan educadores, un presidente (Manuel María Mallarino), políticos y literatos (Guillermo Valencia y Carlos Martínez Silva), Santiago Martínez Delgado desde muy joven sintió una fuerte y decidida inclinación por las artes y las letras. Su primera fuente de inspiración y modelo a seguir fue su propia madre, Mercedes Delgado Mallarino, quien alimentaba una profunda afición a la pintura y el dibujo, intereses que intentaba cultivar día a día. Este fue el escenario donde el pequeño Santiago creció, admirando las formas que su madre dibujaba, y no tardó en comenzar a imitarla con gran talento.

Años más tarde, el joven Santiago Martínez Delgado, al ingresar al Colegio Mayor de San Bartolomé en Bogotá, encontró el lugar indicado para alimentar su vocación por el dibujo en la clase de pintura que dictaba el maestro Roberto Pizano, importante figura del arte de principios del siglo XX en Colombia. Allí, las inquietudes artísticas de Martínez -que se manifestaban en pintar los rostros de sus compañeros de aula-, hallaron una guía inmejorable, ya que Pizano más allá de ser un destacado pintor, era poseedor de una magnífica cultura humanística. Pizano, al ver las excepcionales cualidades del joven Martínez Delgado, le ofreció oportunidades de formación avanzada en la Escuela de Bellas Artes de Bogotá, a la cual pertenecía como uno de sus más destacados profesores.

La familia Martínez Delgado, que a pesar de su tradición y pasado no era propiamente acomodada, recibió para ese entonces una noticia que parecería acabar con la promisoria formación artística del joven Santiago. Mientras participaba en una actividad de cultura física de su colegio, producto del esfuerzo realizado debió ser atendido por un médico, quien le diagnóstico una afección cardíaca. El dictamen médico le recomendaba que debía trasladarse a una ciudad a nivel del mar, con el fin de prevenir futuras complicaciones en su salud, debido a que la altura de Bogotá ( $2.600 \mathrm{msnm}$ ) no era recomendable para su recién descubierto estado.

Ante las limitaciones económicas de su familia que impedían un viaje y permanencia cómoda en Barranquilla o Cartagena para continuar su formación académica, Santiago debió aventurarse hacia el Caribe colombiano en busca de nuevas oportunidades para su vida. Allí, para obtener medios de subsistencia se ocupó en diferentes oficios: agente de policía en Barranquilla en un principio y, posteriormente, como carguero del puerto cartagenero.

A pesar de estas dificultades, el joven Santiago no olvidaba sus intereses intelectuales y es así como bajo el seudónimo "Sanmardel”, envió un cuento al periódico La Patria de Cartagena, publicado en 1924 con notable reconocimiento. Posteriormente, continuó colaborando con esta publicación, cubriendo una noticia acerca del fantasma del Cabrero, personaje fantasioso que llenaba de interés a toda la población cartagenera, convirtiéndose en 
el principal cronista de estos acontecimientos. De esta manera, ingresó a formar parte del equipo de reporteros del periódico para temas culturales y entrevistas a los ilustres visitantes a la ciudad, los cuales no solo eran entrevistados, sino también dibujados por el mismo Santiago.

Fue tan valiosa su participación en el periódico, que el 8 de mayo de 1925 el joven cronista y dibujante bogotano fue encargado de la página literaria, tribuna en la cual pudo plasmar sus cualidades intelectuales. En esas nuevas circunstancias y superadas las dificultades económicas y de salud, el joven Martínez Delgado entró en contacto con lo más selecto de la cultura cartagenera, logrando alimentar su faceta literaria, la cual se hizo evidente en su libro de poemas Efigies y Medallones, editado por la Tipografía Parias de Barranquilla en 1926.

Ante la cotidianidad de la labor periodística que desempeñaba, Santiago Martínez Delgado cultivó el dibujo de acuerdo con los requerimientos de su vida de reportero, faceta de ilustrador que le abriría en 1928 las puertas de regreso a Bogotá, donde comenzó a colaborar en publicaciones como Cromos, Mundo al Día y El Gráfico, esta última en calidad de director artístico desde septiembre de ese mismo año. Por entonces trabajaba escribiendo cuentos y relatos, actividad que acompañaba con la ilustración de textos poéticos e históricos, en los cuales evidencia su calidad como dibujante en portadas memorables de El Gráfico. Allí, su trazo consistente y seguro comenzó a volverse un sello propio de la identidad de la revista.

Para ese entonces, Antonio Martínez Delgado, hermano mayor de Santiago, fue nombrado por el Ministerio de Relaciones Exteriores como cónsul general de Colombia en Chicago, debido a su formación académica en comercio exterior y a su conocimiento de idiomas. Este acontecimiento fue la oportunidad para que el joven Santiago pudiera continuar sus estudios contando con el apoyo y la posición de su hermano mayor. Así fue como viajó junto a su hermano Antonio a los Estados Unidos para matricularse en la Academia de Bellas Artes de la ciudad de Chicago.

Ingresar a una de las academias de arte más importantes del mundo en aquel tiempo, le permitió conocer de primera mano el movimiento de las artes y sus metodologías de trabajo, así como entrar en contacto con figuras como Frank Lloyd Wright, Charles Morgan y Ruth Ford. Esta última no solo fue la encargada de asesorar y acompañar el proceso de iniciación de Santiago en la escuela, sino de manejar los fondos económicos que cubrirían los gastos del nuevo estudiante. El esfuerzo y empeño de Martínez Delgado se vio reflejado en su alta disposición para emprender el trabajo académico, lo cual fue acompañado en su actividad como ayudante de la cafetería de la academia, oficio que desarrolló con el fin de aportar para su sustento como estudiante. En reconocimiento a su dedicación y empeño, la dirección de la Academia le permitió continuar sus estudios a pesar de que sus fondos se habían agotado, asegurando la culminación de su formación artística. En su trasegar como estudiante de la Academia de Bellas Artes de Chicago (1929-1931), Martínez tomó cursos avanzados de historia del arte, dibujo, grabado, composición, técnicas pictóricas, talla en madera y escultura, haciendo énfasis en decoración y en las artes publicitarias. A medida que avanzaba en su formación, se pudo acercar a las grandes colecciones de pintura y escultura del mundo entero, comprendiendo que sería de gran importancia estudiar el patrimonio pictórico de Colombia, comenzando a germinar la idea de regresar a su país natal para secundar un movimiento de rescate y 
reivindicación del arte colombiano de la Colonia y el siglo XIX, actividad que en distintas épocas habían iniciado Alberto Urdaneta y Roberto Pizano, su maestro en las épocas de colegio.

Mientras adelantaba sus estudios artísticos, Martínez realizó múltiples encargos profesionales, como ilustraciones para diferentes publicaciones norteamericanas, entre las que destaca la revista Esquire. Es así que, en 1933, con motivo de la exposición mundial de Chicago, realizó quizás su primera obra realmente importante, el mural La evolución cultural de Colombia, que infortunadamente no figuró en el pabellón de Colombia, sino en el de la General Exhibits Group. Con este trabajo ganó el Premio Logan, uno de los más importantes del arte norteamericano, gracias a su estilo innovador, estilizado y la línea generosa de su trazo. De la misma manera, y como evidencias de su destacado proceso de formación, Martínez ganó en 1934 uno de los doce premios en el concurso nacional para el mejor aviso del año otorgado por la Federación de Artistas Comerciales de los Estados Unidos, así como el segundo premio en el concurso de interpretación pictórica organizado por The Chicago Tribune.

Su permanencia en Chicago le permitió conocer a grandes personalidades en el ámbito de la cultura y las artes de su tiempo, siendo la figura del reconocido arquitecto Frank Lloyd Wright la más importante de todas ellas. El interés por comprender las teorías arquitectónicas de carácter funcionalista y de armonía con el entorno trazadas por el más reconocido arquitecto de ese entonces, sumado al talento indiscutido de Martínez Delgado, hicieron que entre ambos surgiera una sincera y fructífera relación académica, la cual evolucionó hacia la solicitud de encargos profesionales para la realización de trabajos de vitrales y tallas. Por invitación del propio Frank Lloyd Wright, el estudiante colombiano tuvo la oportunidad de participar en jornadas de trabajo en Taliesin, el centro taller que Lloyd Wright estableció en Arizona para estudiar los problemas de diseño y de la arquitectura contemporánea, aprendiendo del maestro su postura filosófica acerca de la capacidad de adaptación que tiene el ser humano a las circunstancias contemporáneas de vivienda, desplazamiento y cultura.

Al graduarse en 1931 como Master in Fine Arts, la Academia de Bellas Artes de Chicago le ofreció un cargo para formar parte del equipo de profesores de la escuela, pero ante el fallecimiento de su hermano mayor Antonio y el debilitamiento del estado de salud de su madre, Santiago decidió regresar a Colombia para ocuparse de los asuntos familiares.

El regreso de Martínez Delgado a su país se enmarcó en el encargo de la Dirección de Edificios Municipales para que diseñara el telón de boca del Teatro Municipal de Bogotá, representando el triunfo de la comedia sobre la tragedia, obra con la que obtendría gran reconocimiento por parte de toda la sociedad capitalina. Lo anterior fue acompañado con una exposición de su trabajo, la cual abrió sus puertas el 10 de enero de 1935 en la Escuela Departamental de Artes con el auspicio de la Secretaría de Educación de Cundinamarca. Con esta muestra -que iba más allá de la tradicional exposición pictórica-, se despertó una fuerte controversia en la prensa bogotana, ya que el trabajo de Martínez Delgado era tan heterogéneo que albergaba óleos, dibujos, ilustraciones de libros y revistas, grabados, acuarelas, tallas en madera y pirograbados, lo que generó desconcierto y comentarios tan disímiles en reporteros y críticos como Hernando Téllez, Jorge Zalamea, Adel López Gómez, J. M. Álvarez Donsorville y Abelardo Forero Benavides, quienes 
no dudaron en tildarlo con algo de sarcasmo de "habilísimo decorador", abriendo la puerta al arte decorativo como escenario innovador de la cultura artística de los años treinta (Álvarez, 1935, p. 40).

No contento con la revolución causada en los medios culturales de su ciudad natal, Martínez Delgado organizó una segunda exposición a la que tituló Cosas y motivos de decoración interior, abierta al público el 20 de abril de 1936 en el Teatro Municipal de Bogotá. En esta muestra se presentaban productos de diversa naturaleza, lo que llevó al comentarista Luis Eduardo Nieto Caballero a escribir:

...bajo la modesta denominación de cosas y motivos decorativos, [Santiago Martínez Delgado] presentó al público una serie de muebles, diseños de tapices, lámparas, porcelanas, tallas de madera, mayólica y cerámicas. La decoración interior es, como toda manifestación de gusto íntimo y personal, un arte de la minoría. Y cuando para lograr una severa y propicia realización se cuenta con la capacidad creadora y sutil de Martínez Delgado, parece que es posible darle sentido de revaluación, de novedad, que enaltece el aparente significado trivial que merece, en concepto de algunos (Nieto, 1936, p. 88).

El factor renovador y los aires de cambio que habían traído el trabajo de Santiago Martínez Delgado fue observado con detenimiento por la floreciente industria y el comercio, quienes vieron en las artes decorativas un nuevo espacio donde la versatilidad del artista era enmarcada en un nuevo sentido estético desconocido hasta ahora por la sociedad bogotana. De esta manera, la Compañía Colombiana de Seguros (posteriormente Colseguros), la más importante y tradicional aseguradora de este país, contrató en 1936 a Martínez Delgado para que formara parte del Departamento de Dibujo y Publicidad, con la responsabilidad de orientar las artes gráficas y la comunicación publicitaria al servicio de los objetivos económicos y sociales de la empresa. Así, la aseguradora encontró un eficaz colaborador en el desarrollo de campañas publicitarias que buscaban crear la necesidad de adquirir un seguro en el medio colombiano, poco acostumbrado a ello.

Un estilo nuevo y una eficiente estrategia cultural comenzó a aparecer en los avisos publicitarios de la Compañía Colombiana de Seguros. Periódicos y revistas mostraban avisos innovadores que contrastaban con las ideas rígidas, literales y lapidarias de ese entonces, apareciendo ilustraciones magníficas con dibujos estilizados en medio de composiciones sugestivas que complementaban las intenciones comunicativas que se buscaba propagar entre los lectores. Por medio de acertados e inteligentes recursos artísticos se expresaban sentimientos e ideas relacionadas con el sentido de los valores familiares y la defensa de su patrimonio.

El mejor medio para la difusión de estas ideas fue la revista Vida, órgano de expresión de la Compañía Colombiana de Seguros, dirigida por Alberto Mejía Botero y presentada en noviembre de 1935, poco a poco se fue convirtiendo en una de las más afortunadas expresiones de la renovación de las artes gráficas colombianas de esa década. Allí, el dibujo y el talento de Santiago Martínez Delgado encontrarían una magnífica oportunidad para formar parte de una de las más interesantes iniciativas de la cultura nacional de ese tiempo. Con el lema "Servir, servir más y servir mejor", la publicación 


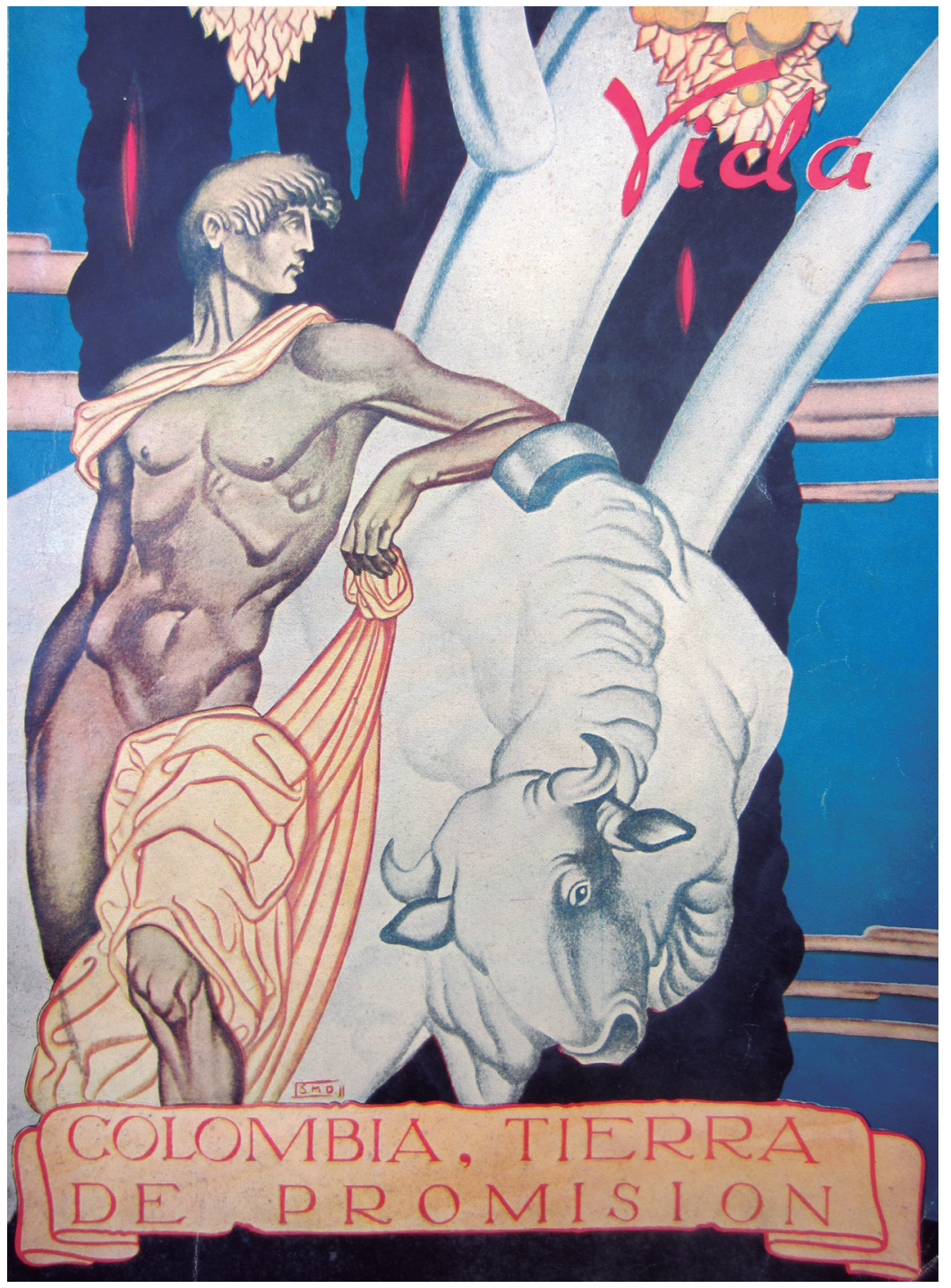

pretendía convertirse, en palabras de los directivos de la aseguradora, en la preferida de la mujer, del niño, del comerciante, del industrial y del hombre de negocios, privilegiando la producción de escritores y artistas colombianos, fomentando y estimulando el esfuerzo nacional en todos sus aspectos. Sus objetivos explícitos estaban dirigidos a beneficiar los intereses públicos y los de la compañía, buscando que sus páginas fueran un modelo por su diseño, estilo y moralidad al servicio de la cultura colombiana.

Santiago Martínez Delgado se convirtió en el director artístico de Vida en su primera etapa (1935 a 1940) y acreditó, por medio de sus páginas, las nuevas posibilidades editoriales, litográficas y tipográficas de su tiempo con eficacia, precisión y esmero, logrando un testimonio editorial solo comparable con la revista Pan, editada en Cali por Enrique Uribe White. La capacidad y las posibilidades de los sistemas de impresión fueron explorados en profundidad por Martínez Delgado, no solo por su condición de dibujante y diagramador, sino también de cronista cultural, redactor e impresor de la revista, lo cual expresó por medio de bellas, elegantes y estilizadas ilustraciones, títulos y
Figura 2. Ilustración, Portada Revista Vida. Fuente: Vida, (40). 

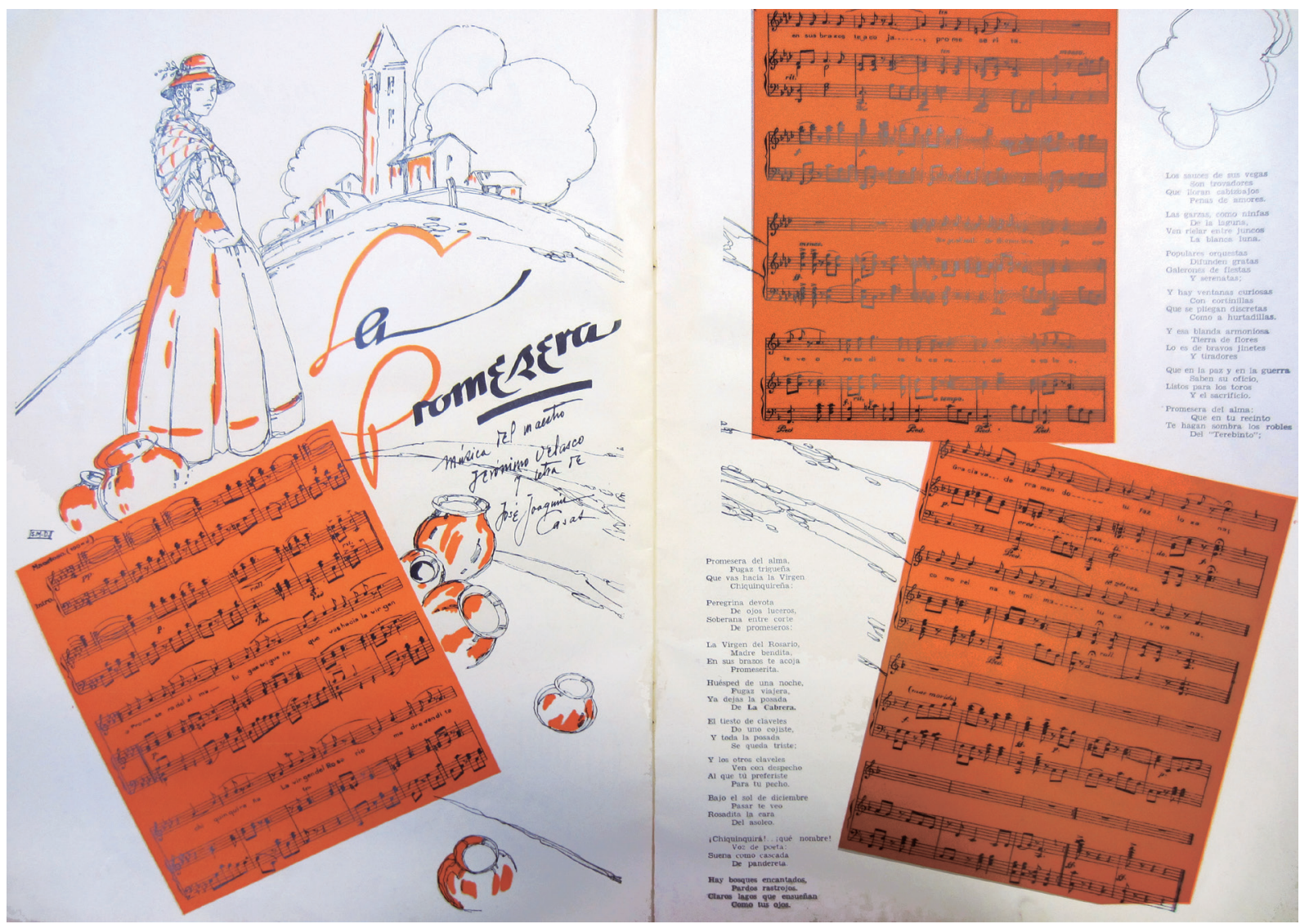

Figura 3. Doblepágina, Revista Vida. Fuente: Vida, (21), 22-23. avisos publicitarios que recogían de manera sobresaliente la interpretación de costumbres y personajes de una época.

Paralelamente, y aprovechando su condición de director artístico de la revista Vida, Martínez Delgado trabajó en inventariar el patrimonio artístico colombiano, lo que lo llevó a participar en la realización de un catálogo preliminar, preparativo y general del arte nacional en conjunto con el Patronato Colombiano de Artes y Ciencias. Por las páginas de Vida pasaron numerosos cuadros que hasta ese entonces solo habían sido conocidos y apreciados en escenarios familiares muy restringidos, permitiendo que un segmento más amplio de la sociedad se aproximara a obras del arte colombiano casi totalmente desconocidas.

En 1940 el colegio Externado Nacional Camilo Torres realizó su Semana de la Cultura, donde la Exposición del Renacimiento en Bogotá, cuyo montaje ejecutó, puso en contacto a millares de estudiantes de bachillerato por primera vez con el arte renacentista a través de un juicioso y metódico conjunto de óleos y pinturas representativos de esa etapa. De esta manera, Martínez Delgado manifestaba los logros de su estancia en Chicago en su interés por rescatar y poner en valor para la vida cultural el patrimonio pictórico y artístico que se presentaba oculto para muchos de sus coterráneos, una de las facetas más interesantes y desconocidas de su vida.

Hacia 1940, su trabajo en la revista Vida y sus acciones a favor de la difusión y defensa del patrimonio cultural alcanzan el reconocimiento suficiente como para independizarse, fundando su propia agencia de publicidad, donde 


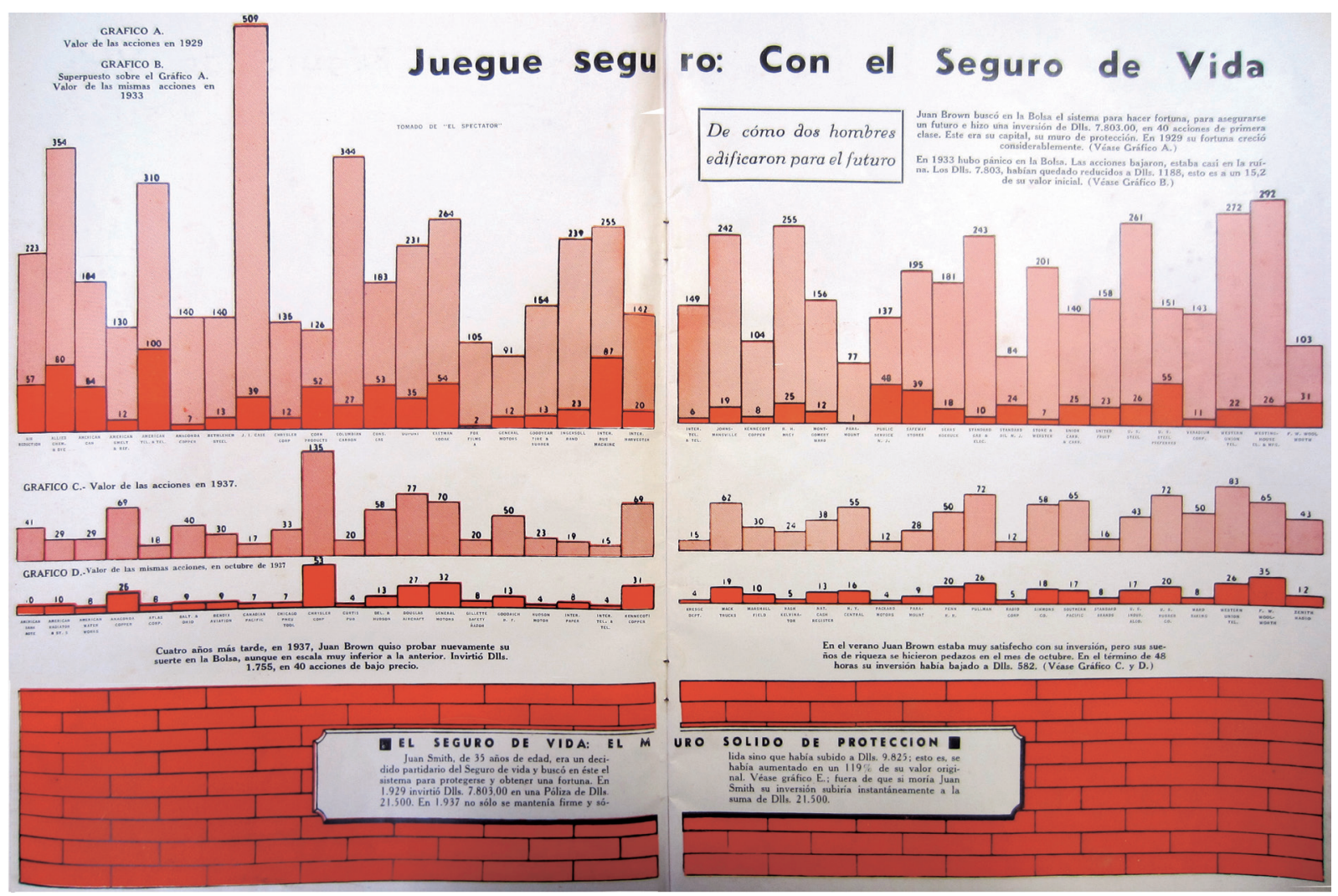

avizoró nuevos horizontes para la comunicación publicitaria, produciendo avisos de gran factura y de clara intención comercial. Asimismo, se dedicó con gran acierto a escribir programas radiales de carácter histórico y literario, como lo fueron El Virrey Solís, Estampas navideñas y Tierra a la vista.

Poco a poco, Martínez Delgado enfocó de nuevo sus energías en la pintura y las artes decorativas, tareas que había dejado un tanto olvidadas debido a su trabajo en la Compañía Colombiana de Seguros. De esta manera regresó a la pintura, siendo merecedor en 1940 de una medalla de oro por su trabajo El que volvió, cuadro que pone en evidencia el éxodo campesino hacia las ciudades. Un año más tarde ganó el Primer Premio del Salón Nacional de Pintura con el óleo Interludio, dando inicio a una etapa muy fecunda de producción intelectual.

Su vocación por las letras, iniciada de manera temprana en sus años juveniles en Cartagena, donde sus cuentos y poemas alegraron las páginas de periódicos y libros, son solo una prueba de su connotada y multifacética condición humanista. Escribía con decoro gramatical y un garboso sentido literario, lo que, acompañado con su talento como dibujante, lo condujo a realizar sobresalientes series de ilustraciones que llenaron de exquisitez las páginas de la revista Vida. Basado en sus destrezas, Martínez Delgado fue un destacado intérprete de la vida social, política y cultural de los tiempos de la independencia, llevándolo a plasmar con la pluma y el pincel interesantes estudios sicológicos de iconografías del Libertador, de Francisco de Paula Santander y de otros personajes de la vida republicana del siglo
Figura 4. Infografía, Revista Vida. Fuente: Vida, (73), 12-13. 


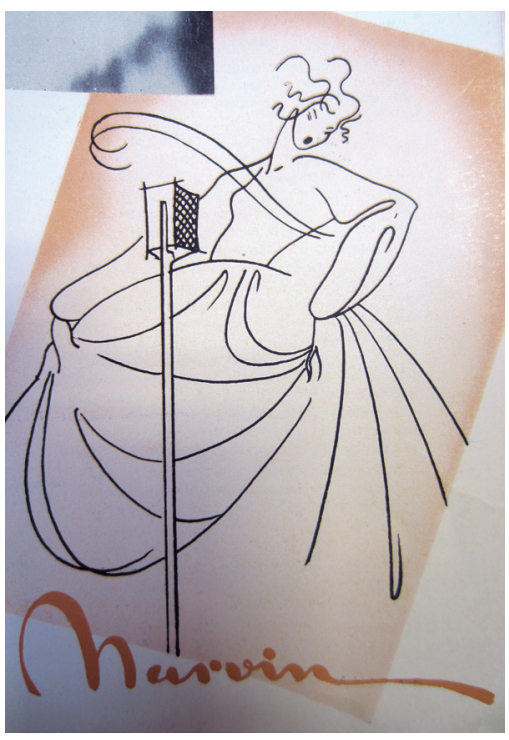

Figura 5. Aviso publicitario, Revista Vida. Fuente: Vida, (36), 63.
XIX. Ejemplos de ello son sus trabajos Iconografía de las armas libertadoras y Ensayo iconográfico del Mariscal Antonio José de Sucre.

Posteriormente, llevó a cabo proyectos pictóricos de gran valor, destacándose el mural que la curia de Cúcuta le encomienda para su catedral bajo el tema del Vía Crucis, así como el encargo que le hiciera el Banco Comercial Antioqueño para que decorara las paredes de sus sedes de las ciudades de Medellín y Cúcuta con sendos murales. Por su parte el Estado colombiano le confía la ejecución del mural del Salón Elíptico del Capitolio Nacional, su obra pictórica más destacada y con la que alcanza su consagración como artista. Se trata de un tríptico que además de representar el Congreso Constituyente de Cúcuta, evidencia las costumbres, el vestuario, el clima y las actitudes de principios del siglo XIX en Colombia. Para la realización de este monumental fresco, que se presentó oficialmente en la instalación de la IX Conferencia Panamericana de Bogotá en abril de 1948, Santiago Martínez dedicó tres años de trabajo sin descanso.

Martínez Delgado continuó su trabajo como cabeza de su propia agencia de publicidad, actividad que combinó con múltiples proyectos pictóricos, escultóricos, radiales y hasta cinematográficos. Este destacado muralista, ilustrador, tallador, dibujante, editor, pintor, periodista, cuentista, libretista, publicista, impresor y cronista, fallece en Cajicá el 12 de enero de 1954, dejando una invaluable obra que evidencia su magnífica formación artística que recoge una sólida fundamentación humanística. Su vida y su obra lo hicieron un hombre múltiple que, basado en su inteligencia y talentos privilegiados, logra estilizar un lenguaje gráfico con recursos modernos basados en el concepto de funcionalidad y eficacia, logrando discursos influyentes y determinantes para el arte, la propaganda comercial y las artes decorativas y gráficas de su época. 


\section{Bibliografía}

Álvarez, J. (1935). Martínez Delgado y el arte decorativo. El Gráfico, 40.

Bloch, M. (2001). Apología para la historia o el oficio del historiador. Ciudad de México: Fondo de Cultura Económica.

Burke, P. et al (1993). Formas de hacer Historia. Madrid: Alianza Editorial.

Cárdenas, J. y Ramírez, T. (1986). Evolución de la pintura y escultura en Antioquia. Medellín: Museo de Antioquia.

Castro-Gómez, S. (1999). Pensar en los intersticios. Bogotá: Pontificia Universidad Javeriana.

De Certeau, M. (1993). La escritura de la historia. Ciudad de México: Universidad Iberoamericana.

Didi-Huberman, G. (1997). Lo que vemos, lo que nos mira. Buenos Aires: Manantial.

Duque, P. (2009). Cartel ilustrado en Colombia: década 1930-1940. Bogotá: Universidad de Bogotá Jorge Tadeo Lozano.

González, B. (2009). La caricatura en Colombia a partir de la Independencia. Bogotá: Banco de la República.

[llustraciones de Santiago Martínez Delgado]. (Bogotá, 1939-1941). Revista Vida (21, 36, 40, 73).

Henderson, J. (2001). La modernización en Colombia. Los años de Laureano Gómez 1889-1965. Medellín: Universidad Nacional de Colombia.

Hobsbawm, E. (2004). Sobre la historia. Barcelona: Crítica. Jameson, F. (2004). Una modernidad singular. Buenos

Aires: Gedisa.

Jaramillo, C. (2005). Arte, política y crítica: una aproximación a la consolidación del arte moderno en Colombia. Bogotá: Universidad Nacional de Colombia.

Koselleck, R. (1993). Futuro pasado. Madrid: Paidós. Londoño, S. (2002). El arte en la publicidad. Nacional de Chocolates 1920-1960. Bogotá: Panamericana.

Mallarino, V. (1936). Crónicas de arte y sociedad a cargo de Víctor Mallarino: La exposición de Santiago Martínez Delgado. El Tiempo, 4-5.

Medina, A. (1994). El arte colombiano en los años veinte y treinta. Bogotá: Colcultura.

Meggs, P. (1991). Historia del Diseño Gráfico. Ciudad de México: Trillas.

Nieto, L. (1936). El arte de Santiago Martínez

Delgado. Lecturas Dominicales, 88.

Pini, I. (2000). En busca de lo propio. Inicios de la modernidad en el arte en Cuba, México, Uruguay y Colombia. Bogotá: Universidad Nacional de Colombia.

Piñeros, J. (1974). Santiago Martínez Delgado: el pintor, el humanista, el colombiano. Bogotá: Compañía Colombiana de Seguros.
Samper, A. (1989). Historia de la caricatura en Colombia. Bogotá: Banco de la República.

Silva, R. (2005). República liberal, intelectuales y cultura popular. Medellín: Editorial La Carreta.

Singerman, B. (1928). Fantasía negra. Bogotá: Litografía Colombia.

Uribe, C. (1985). Los años veinte en Colombia. Ideología y cultura. Bogotá: Ediciones Aurora.

Uribe White, E. (1938). Propaganda bogotana 1938.

Revista Pan, (23), 55-59.

Zalamea, J. (1938). Imagen de la ciudad. Revista de las Indias, (2), 10.

Zalamea, J. (1941). Nueve artistas colombianos. Bogotá: Litografía Colombia. 